\title{
Habitat amount is less important than habitat configuration for a threatened marsupial predator in naturally fragmented landscapes
}

\author{
Harry A. Moore ${ }^{(\mathbb{D} \cdot}$ Damian R. Michael \\ Judy A. Dunlop · Leonie E. Valentine • \\ Mitchell A. Cowan · Dale G. Nimmo
}

Received: 22 August 2021 / Accepted: 27 January 2022 / Published online: 12 February 2022

(C) The Author(s) 2022

\begin{abstract}
Context The amount and configuration of habitat are independent but tightly linked landscape characteristics which are often confounded in ecological studies. Differentiating the effects of each characteristic is critical for conservation, because the mechanisms by which they influence populations are
\end{abstract}

Supplementary Information The online version contains supplementary material available at https://doi. org/10.1007/s10980-022-01411-1.

H. A. Moore $(\bowtie) \cdot$ J. A. Dunlop · M. A. Cowan ·

D. G. Nimmo

School of Agricultural, Environmental and Veterinary

Sciences, Charles Sturt University, Albury, NSW 2640,

Australia

e-mail: harryamos@live.com.au

H. A. Moore · J. A. Dunlop · L. E. Valentine ·

M. A. Cowan

School of Biological Sciences, University of Western

Australia, Crawley, WA 6009, Australia

D. R. Michael

Gulbali Institute, Charles Sturt University, Albury,

NSW 2640, Australia

J. A. Dunlop

Department of Biodiversity, Conservation and Attractions, Bentley Delivery Centre, Locked Bag 104, Perth, WA, Australia

J. A. Dunlop

Western Australian Feral Cat Working Group, Perth, WA 6000, Australia distinct. While studies that have measured the effects of habitat amount and configuration separately have often found the former to be more important, a subset of these studies suggest habitat configuration can be vital to a species when habitat amount is low (10-30\%).

Objectives We aimed to test the independent effects of habitat amount and configuration on the occupancy and abundance of an endangered marsupial predator, the northern quoll (Dasyurus hallucatus), which persists in naturally fragmented rocky landscapes, in which habitat amount is naturally low (i.e. typically $<30 \%$ ).

Methods Northern quolls were surveyed across 22 study landscapes that were deliberately selected such that habitat amount and configuration were uncorrelated. Northern quoll occupancy and abundance was estimated at each landscape using data collected from remote sensing cameras, and a combination of occupancy and n-mixture models.

Results Spatial configuration of rocky habitats was more important than the amount of habitat when predicting quoll occupancy and abundance; northern quolls were less abundant in landscapes that were more fragmented. In addition, northern quolls favoured areas that were topographically rugged and received more rainfall.

Conclusions Our results support the hypothesis that the effects of habitat configuration can be strongest when habitat amount is low, and underscore the importance of aggregated patches of rocky outcrops 
for northern quoll conservation. The subdivision of rocky habitat, for instance through construction of mines or mining infrastructure (e.g. road, rail lines), is likely to have negative impacts on northern quoll populations.

Keywords Landscape ecology · Predator . Fragmentation · Threatened species $\cdot$ Habitat configuration $\cdot$ Predation

\section{Introduction}

The relative importance of habitat amount and configuration in shaping species' distributions and abundance has been debated for decades (Andren 1994; Fahrig 2003). Habitat amount refers to the area of habitat within a landscape, whereas habitat configuration refers to its spatial arrangement (Fahrig 2003). Understanding the relative influence of each is important in fragmented landscapes, where patches of 'habitat' exist within a matrix of less suitable or hostile "non-habitat", and conservation planners must prioritise areas of habitat for protection or restoration (Fahrig 2003; Haddad et al. 2015). In such instances, a key question is whether to maximise the overall amount of habitat-irrespective of the isolation or connectivity among habitat patches-or whether the configuration of habitat (e.g., the dispersion of habitat patches) also warrants consideration (Villard and Metzger 2014).

The "fragmentation threshold" hypothesis states that configuration will be most important in landscapes with relatively little habitat (i.e., $<20-30 \%$ ) where connectivity between habitat patches is diminished, making species' abundance more contingent upon the size and isolation of habitat patches (Andren 1994). This hypothesis has received mixed support. For example, using simulations, Fahrig (1998) found fragmentation only had an important effect on species survival when habitat cover used for breeding was less than 20\%, whereas Villard and Metzger (2013) and Melo et al. (2017) found configuration was most important at intermediate values of habitat amount. McGarigal and McComb (1995) showed habitat area was always more important than habitat configuration in predicting the abundance of breeding birds in north-west America, regardless of the amount of habitat present within a landscape.
Most studies of habitat amount and configuration have focussed on human-modified landscapes, in which 'habitat' is comprised of remnant vegetation within a matrix of modified land or 'non-habitat' (e.g. farmland or urban areas). Yet, many landscapes are naturally fragmented (sensu Bleich et al. 1990; Watson and Peterson 1999; Driscoll 2005), defined as habitat patches embedded in a relatively unmodified matrix that is nonetheless unsuitable to a given species. By contrast to landscapes fragmented by humans, habitat patches in naturally fragmented landscapes often arise through geological or climatic processes that leave them exposed or restricted, similar to oceanic islands (Fitzsimons and Michael 2017). It's important to consider that differences in how human and naturally fragmented landscapes are formed have the potential to influence how species respond to them in terms of habitat amount and configuration.

Rocky outcrops are a prime example of naturally fragmented habitat patches found on all continents (Porembski and Barthlott 2000; Bayly 2011; Michael and Lindenmayer 2018). As geological features that protrude beyond the surrounding land, they can be described as 'small natural features'-environments that occupy a relatively small geographic space but have ecological effects that extend well beyond their boundaries (see Hunter et al. 2017). Other examples of small natural features include coral reefs, desert springs, and large, old trees (Hunter et al. 2017). Such features typically comprise a limited amount of habitat, often well below the hypothesised fragmentation threshold of $20-30 \%$. Consequently, according to the fragmentation threshold hypothesis, habitat configuration will be a primary driver of species' distributions and abundance in such landscapes.

The time scale over which human and naturally fragmented landscapes have been present may also influence how species are able to use them. For instance, species that have long occurred in naturally fragmented landscapes, formed thousands to millions of years ago, are often adapted to dealing with the challenges of persisting in patchy habitat (Cheptou et al. 2017)—Thomas et al. (1998) and Hill et al. (1999) found butterflies that occurred in more fragmented habitats were potentially better dispersers than butterflies in less fragmented habitat, which may allow them to overcome increased rates of local extinction. By contrast, species occurring in human fragmented landscapes are unlikely to have had the 
opportunity for this kind of evolution to occur, and thus the impacts of fragmentation on populations in terms of occupancy and abundance are likely to be more noticeable.

In addition to habitat amount and configuration, Bennett et al. (2006) outline two other important landscape properties that can influence species distributions: landscape composition and environmental gradients. Landscape composition refers to the types of elements present within a landscape and their relative proportions (Bennett et al. 2006). One important component of landscape composition is the condition of the matrix surrounding favoured habitat (Ewers and Didham 2006; Kupfer et al. 2006). Matrix condition can influence species inter-patch movement (Bender and Fahrig 2005), as well as the availability of supplementary resources (Öckinger et al. 2012), and the intensity of edge effects (Haynes and Cronin 2006). Matrix effects may be particularly strong in fire-prone landscapes, where the structure and composition of matrix vegetation is in a constant state of flux as a result of being periodically incinerated (Nimmo et al. 2019). Finally, environmental gradients, such as rainfall or topography, drive species distributions and abundance by dictating local climatic conditions and resource availability (Nimmo et al. 2013; McDonald et al. 2015; Moore et al. 2019).

In this study, we test the effects of habitat amount and configuration as well as landscape composition and environmental gradients on the occupancy and abundance of an endangered marsupial predator in 12 naturally fragmented landscapes. The northern quoll (Dasyurus hallucatus) once occurred across northern Australia, but has suffered broad scale population decline (Braithwaite and Griffiths 1994; Moore et al. 2019) as a result of changing fire regimes (Woinarski et al. 2011), predation (Oakwood 1997; Cremona et al. 2017), and the invasive cane toad (Rhinella marina) which is fatally toxic when consumed (Oakwood 2004). Understanding the effects of habitat amount and configuration on the northern quoll is of critical importance for the species, particularly in the Pilbara bioregion - the only section of the northern quoll range yet to be invaded by cane toads, and regarded as a stronghold for the species (Cramer et al. 2016). Here, northern quolls occur within topographically rugged, naturally fragmented landscapes comprising rocky outcrops of granite and iron-stone formations over 2.6-2.7 billion years old (Withers
2000) which are surrounded by a matrix of fire-prone spinifex grasslands. Although typically comprising a small proportion of the landscape (i.e., $<30 \%$ ), rocky outcrops are prime habitat for quolls and a suite of other species (Michael and Lindenmayer 2018; Moore et al. 2021b). Quolls typically avoid moving through the sandplain matrix, likely to avoid larger predators like feral cats (Felis catus) and dingoes (Canis dingo) (Hernandez-Santin et al. 2016). The risks associated with moving through the spinifex matrix are exacerbated after fire, which removes vegetation structure, thereby improving the hunting efficiency of predators of the northern quoll (McGregor et al. 2015). Sections of the Pilbara's rocky habitat are under threat, or have already been destroyed through iron ore and granite mining activity (Cramer et al. 2016) — a key threat for the northern quoll in the region (Hill and Ward 2010; Woinarski et al. 2014). Defining areas of critical habitat is now a research priority for the northern quoll (Cramer et al. 2016).

We undertake a whole-of-landscape study (sensu Bennett et al. 2006) to reveal the properties of landscapes that enhance the occupancy and abundance of the northern quoll, by carefully selecting study landscapes that span independent gradients in habitat amount (percent cover) and configuration (amount of edge habitat) (Fig. 1), while also capturing variability in matrix condition (extent of the sandplain matrix that has recently burned). We hypothesise that: (i) in accordance with the fragmentation threshold hypothesis, the occupancy and abundance of the northern quoll will be strongly associated with habitat configuration, given the low values of habitat amount in our study landscapes, and (ii) northern quolls will be more common in landscapes that have a lower proportion of recently burned spinifex grassland matrix, due to their vulnerability to predation in such landscapes.

\section{Material and methods}

Study area

This study was carried out across a $6000 \mathrm{~km}^{2}$ area within the Pilbara bioregion in north-west Western Australia (Fig. 1), encompassing the Kariyarra and Nyamal Indigenous language groups. The study area also overlapped with three cattle stations (Indee Station, Mallina Station, Pippingarra Station), and 

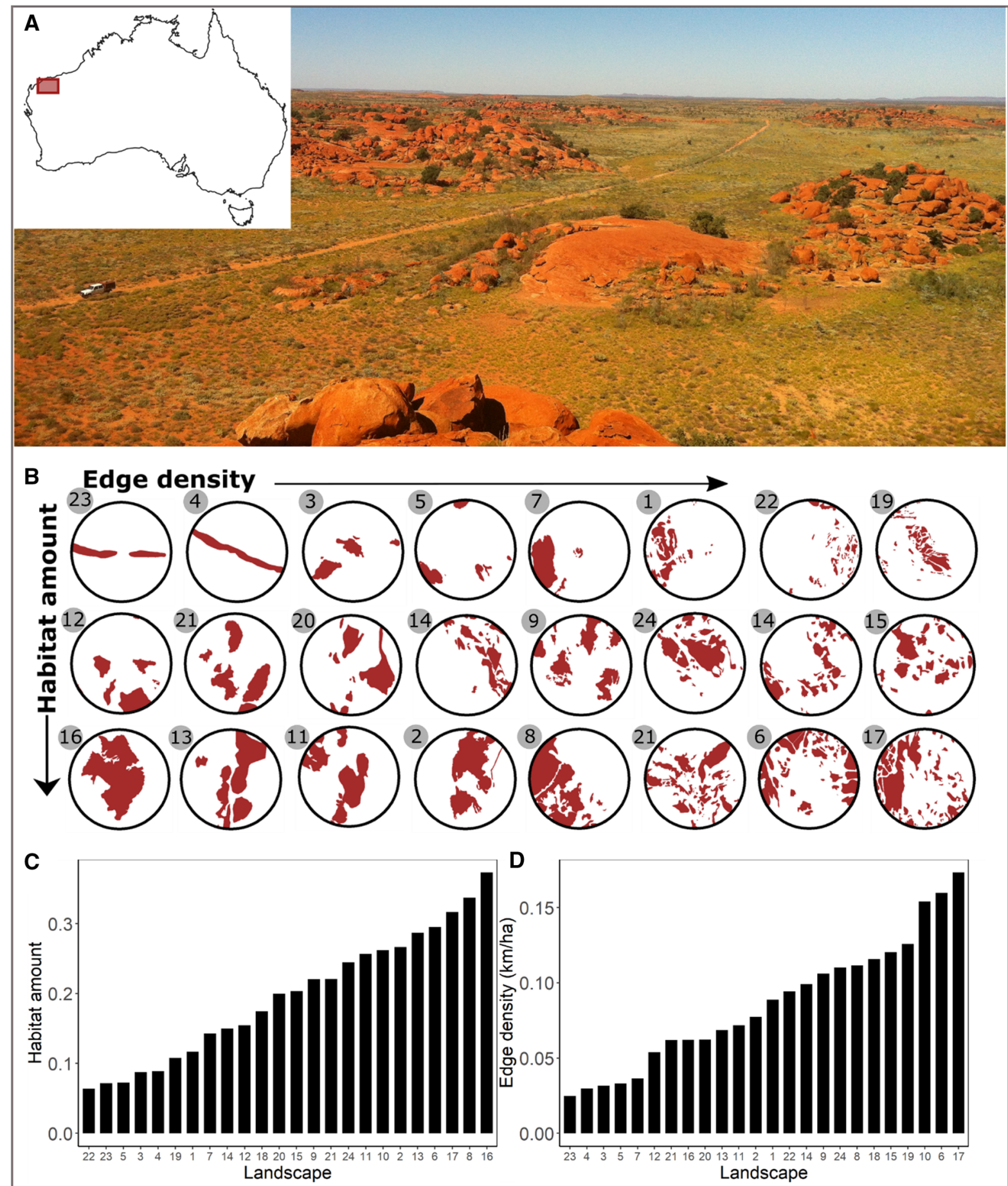

Fig. 1 Study landscapes within the Pilbara bioregion in northwest Western Australia. A Location of the study area in northwest Western Australia and an image of a typical study landscape. B Aerial depictions of the original 24 study landscapes.
Areas shaded red represent rocky habitat, and white areas represent the spinifex grassland matrix. C Habitat amount and D edge density in each of the original 24 study landscapes 
an Indigenous Reserve (Yandeyarra Indigenous Reserve). Vegetation across the study area is dominated by spinifex grasslands, with sparse tree cover comprised of mulga (Acacia aneura), snakewood (Acacia xiphophylla) and snappy gum (Eucalyptus leucophloia). Geology is characterised by largely flat sand plains interspersed with banded ironstone ridges and granite outcrops (Withers 2000). Average daily temperature maximums across the study period ranged from $28.4{ }^{\circ} \mathrm{C}$ (August 2017) to $44.1{ }^{\circ} \mathrm{C}$ (December 2018) (Australian Bureau of Meteorology 2019).

\section{Study design and landscape selection}

Measures of fragmentation, such as the amount of edge or the number of habitat patches within a landscape, are typically correlated with the amount of habitat in a landscape (Fahrig 2003). Here, we aimed to capture non-correlated gradients of habitat amount and configuration (correlation coefficient $<0.5$ ), such that they could be tested independently. We achieved this by selecting landscapes across the habitat amount gradient that varied in the configuration of habitat. First, we selected 60 candidate landscapes comprised of rocky outcrops (habitat) embedded within a matrix of spinifex grasslands (non-habitat) from across the study area using QGIS 3.14.1 (QGIS 2020). Landscapes were circular and covered a total area of $\sim 75$ hectares ( $1 \mathrm{~km}$ diameter), which is sufficient to cover the home range of multiple female northern quolls, which are typically less than 35 ha (Moore et al. 2021a). We chose to use female home ranges as a guide in establishing study landscapes given they are far less variable in size than are male home ranges (Cowan et al. 2020; Hernandez-Santin et al. 2020). Second, candidate landscapes were broken into three categories based on the frequency distribution of rocky habitat amount within them (the habitat amount within landscapes ranged from 6 to 37\%). Landscapes with $<15 \%$ habitat coverage were classed as 'low habitat amount'; landscapes with 15-25\% habitat were classed as 'medium habitat amount', and; landscapes with $>25 \%$ habitat coverage were classed as 'high habitat amount'.

Next, within each habitat amount category, a total of eight study landscapes were chosen to represent different configurations of habitat within that category, ranging from landscapes in which most habitat was aggregated into a few patches, to landscapes in which habitat was dispersed among many patches, characterised by large amounts of edge habitat (Fig. 1). This resulted in 24 landscapes that varied in habitat amount and varied in configuration (amount of edge habitat) for a given habitat amount category. Two landscapes were later excluded from further analysis (medium habitat amount $=1$, high habitat amount $=1$ ) because they were located in close proximity to the installation of a granite quarry, or a major river (factors which may bias results), leaving a total of 22 study landscapes. Landscapes were separated from each other by at least $1 \mathrm{~km}$.

Site selection

Within each landscape, we established five sites. Sites were separated from one another by a minimum of $200 \mathrm{~m}$, and were chosen to represent gradients of habitat quality, outcrop size (area), shape (area-edge ratio), and geomorphology as part of a broader monitoring program within which this study was embedded (Moore et al. 2020b, 2021b). At each site, we deployed a Reconyx PC900 Hyperfire passive infrared triggered camera trap (Reconyx 2020). Cameras were orientated vertically (facing downward), and attached to a wooden tree stake $1.5 \mathrm{~m}$ above the ground, with the camera lens and PIR sensors focused directly at the ground surface using a right-angle bracket (see Moore et al. 2020b). A PVC canister containing approximately $150 \mathrm{~g}$ of bait (fish) was attached to the bottom of the tree stake supporting the camera. All cameras were deployed in areas dominated by rocky outcrops, given it is the preferred habitat of the Pilbara northern quoll (Cramer et al. 2016; Moore et al. 2021b). Vertical-facing cameras are ideal for capturing unique spot patterns on the dorsal surface of northern quolls (Hohnen et al. 2013; Diete et al. 2016; Moore et al. 2021b), which we used to identify individual animals (see "Detection data" section). All cameras were set to high sensitivity, and five images were taken at one second intervals per trigger. Sites were sampled for 60 nights in the Pilbara dry season (August-November) and 60 nights in the wet season (December-March). We used 60 nights as this exceeded the sampling effort required to be $95 \%$ confident of northern quoll absence at sites using vertical cameras (Moore et al. 2020b). 
Predictor variables

Study landscapes were characterized according to the four landscape properties outlined by Bennett et al. (2006) (Table 1); habitat amount, habitat configuration, landscape composition, and environmental gradients. We considered the aerial extent of rocky habitat within a study landscape as the measure of habitat amount (Hernandez-Santin et al. 2016; Moore et al. 2021b). Habitat configuration was measured as the length of edge habitat per hectare within each study landscape. While a number of more complex measures of landscape fragmentation were also considered (e.g. aggregation index, number of patches; Kupfer 2012), preliminary analysis revealed that edge density was the most parsimonious measure of configuration in terms of explaining the occupancy and abundance of northern quolls based on the Akaike Information Criterion (AIC). Our previous research in the same study area showed that northern quolls avoid habitat with high amounts of edge between rocky outcrops and spinifex grasslands (Moore et al. 2021b). Landscape composition was measured as the proportion of spinifex grassland comprising the landscape matrix that had been recently burnt. To measure the impact of fire in the matrix, we measured the proportion of landscapes burnt in the previous three years to sampling, using data collected from the Northern Australian Fire Information database (NAFI 2020).

We used topographical ruggedness and total rainfall in the previous Pilbara wet season (Dec-Mar) as measures of environmental gradients across the study. Topographical ruggedness is an important predictor of northern quoll occurrence across their range (Begg 1981; Braithwaite and Griffiths 1994; Pollock 1999), including in the Pilbara (Molloy et al. 2017; Moore et al. 2019). To measure topographical ruggedness at each landscape, we used elevation data collected at $30 * 30 \mathrm{~m}$ resolution (Geoscience Australia 2008). Then for each cell within a landscape, topographical ruggedness was measured as the difference in elevation between it and the eight cells surrounding it (following Reily et al. 1999). Landscape topographical ruggedness was measured as the mean ruggedness value of all cells within a landscape. Previous wet season rainfall was measured as rainfall during the Pilbara wet season prior to sampling. Rainfall data were sourced from the Australia Bureau of Meteorology (BOM 2020). Northern quoll persistence is typically higher in areas that receive higher amounts of rainfall (Radford et al. 2014; Moore et al. 2019). We used previous wet season rainfall specifically because it is likely an important factor in determining the success of Pilbara northern quoll recruitment (occurring Jan-March), a factor that is critical to northern quoll population persistence (Moro et al. 2019).

\section{Detection data}

Camera trap detections separated by at least $15 \mathrm{~min}$ were defined as independent detection events, as per Diete et al. (2016). We attempted to individually identify quolls within each detection event, unless there were no images within a detection event that were suitable for individual identification. Images that contained less than roughly $30 \%$ of the northern quoll's dorsal surface were immediately excluded from further image analysis unless they contained other distinctive features that could be used to identify individuals (e.g. unusual scarring patterns, missing ears). We used unique spot patterning as well as scarring located on the dorsal surface of animals to identify individuals from camera trap imagery, following an identical process to that described in Moore et al. (2020a, 2021b). Data from all cameras within a landscape were pooled for each trap night - for each trap night within each landscape, we recorded the number of individual quolls recorded across all cameras.

\section{Statistical analysis}

We used measures of occupancy and abundance to model northern quoll responses to landscape properties. At an appropriate scale, occupancy and abundance should be correlated (MacKenzie and Nichols 2004), however, it is important to note that each measure distinct population parameters-occupancy measures the proportion of an area occupied by a species, while abundance measures the numbers of individuals in that area-that may not always covary in response to landscape properties (MacKenzie and Nichols 2004).

All statistical analysis was conducted in $\mathrm{R}$ version 4.0.2 ( $\mathrm{R}$ Core Team 2020), using the unmarked package (Fiske and Chandler 2011). No variables included in this analysis shared pairwise correlations $>0.6$ (Table S1). Separate models were fit for 


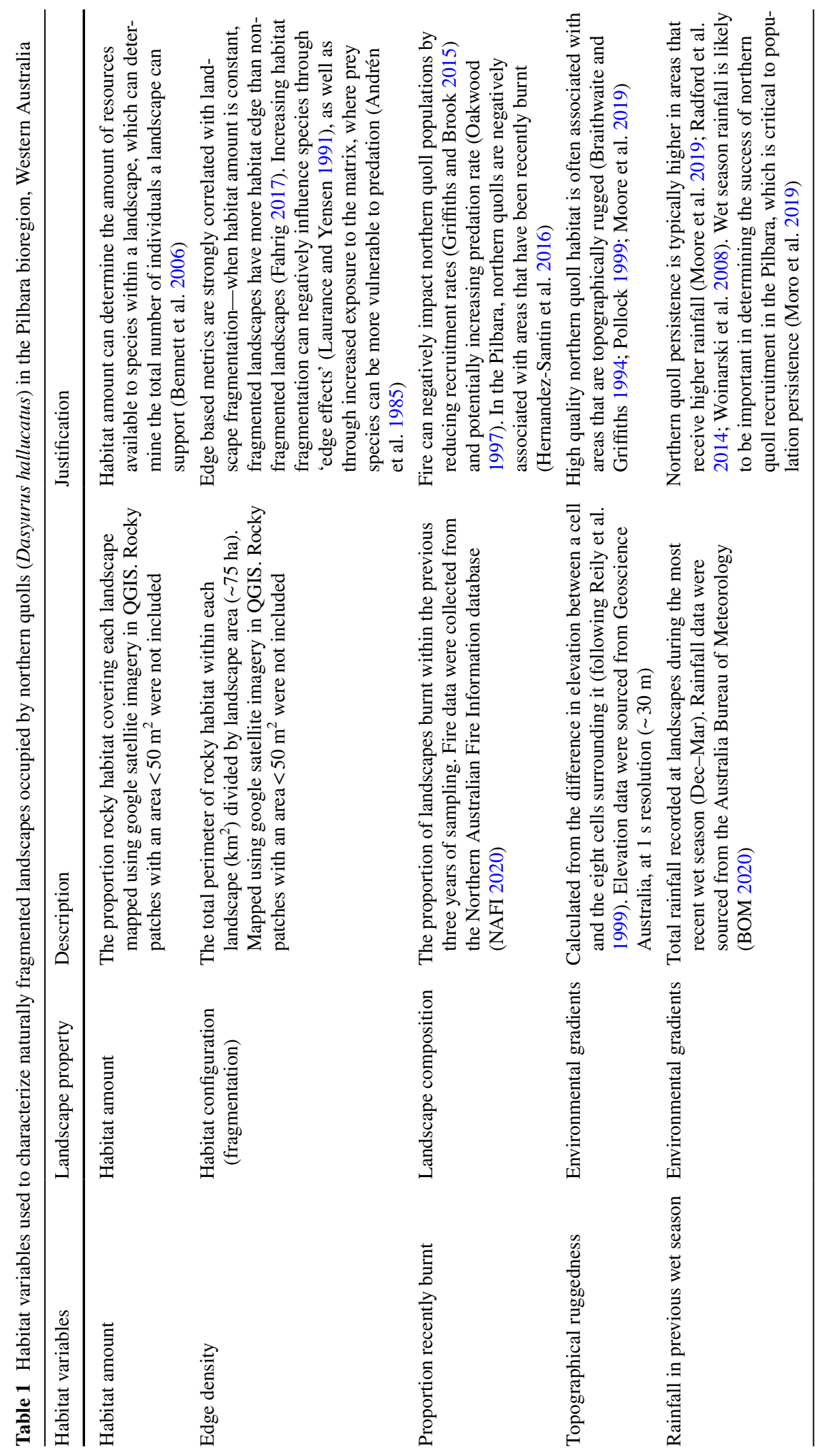


the dry season and wet season to account for differences in occupancy and abundance resulting from varying levels of productivity between seasons and breeding events. Three cameras failed in the dry season sampling period, and three cameras failed in the wet season sampling period. To account for differences in survey effort because of camera failures, all models included total number of trap nights as an offset term, where the maximum was 300 (five sites per landscape*60 nights per season).

\section{Occupancy}

A total of 15 models were fit for each season with a maximum of five parameters per model. Given our primary focus was on habitat amount and configuration, all models included habitat amount and edge density, either as additive terms or with an interaction term between the two. All other combinations of habitat variables were tested (Table 1). No habitat variables were included in the detectability component of the occupancy model, firstly, because the influence of habitat variables on northern quoll detectability was not a focus in this study, and secondly to minimise the number of parameters in models given our low sample size.

Top models were determined using a multistep process outlined in Richards (2008), which aims to reduce the chance of selecting overly complex models. First, models were ranked based on their AIC scores. All models having a $\Delta$-value less than 6 were considered potentially useful, based on the findings of Richards (2008) who found only reporting on models with a $\Delta$-value less than two (as is often the rule of thumb) carries risk of excluding simpler models that may explain variation in the response variable more efficiently. Next, any model with a $\Delta$-value greater than a simpler version (less predictor variables) was removed. Simpler models are often preferable to more complex models when both have similar maximum likelihood scores, given variation in the response variable can be explained using fewer predictors, providing greater inference (Richards 2008). After both of the above steps had been completed, the model with the lowest AICc within each season was considered to be the most parsimonious. Goodness of fit was assessed for the most parsimonious models using a Chi-square test. Predictor variables were regarded as being strongly influential if their $95 \%$ confidence intervals did not overlap zero (Nakagawa and Cuthill 2007).

\section{Abundance}

An identical process as described above was repeated using N-mixture models (Royle 2004), except with input data which was comprised of count data (number of northern quoll individuals detected at a site for each survey night). We also tried to estimate quoll abundance using mark-resight models as part of our preliminary analyses. However, results from these models indicated that they did not perform well, probably because of the sparseness of the data. As such, we restricted our methods for estimating abundance to $\mathrm{N}$-mixture models. $\mathrm{N}$-mixture models are an extension of occupancy models that incorporate detection probabilities into abundance estimates using a combination of binomial and Poisson distribution models from count data (Royle 2004). We fitted N-mixture models using the package unmarked. Preliminary analysis indicated that there were many nights across landscapes where quolls were not detected, leading to zero inflated data. Models that do not account for zero inflation in count data can produce biased parameter estimates (Potts and Elith 2006). To overcome this constraint, we used a zero-inflated Poisson distribution in N-mixture models (Fiske and Chandler 2011). Model selection followed the same approach to that described in the occupancy section.

\section{Results}

Across all landscapes and seasons, we recorded a total of 1004 independent northern quoll detections, a slight majority of which were recorded in the wet season (56.4\%). Most detection events (70.0\%) contained images suitable for individual identification. In total, 136 individual northern quolls were identified. Northern quolls were detected at $68.2 \%$ of study landscapes in the dry season, and $54.5 \%$ of landscapes in the wet season. At landscapes where quolls were detected, the number of independent quoll detections ranged from 1 to 311 . Locations of individual northern quoll detections were uploaded to the publicly available NatureMap repository 
(https://naturemap.dbca.wa.gov.au/). No models tested for goodness of fit showed signs of poor fit.

\section{Occupancy}

In the dry season, the best occupancy model included habitat amount and edge density as additive terms, as well as topographical ruggedness, and the proportion of a landscape that had been recently burnt (Table S3). However, no predictors had a strong influence on northern quoll occupancy (Table 2). In the wet season, the best occupancy model included an interaction term between habitat amount and edge density, with edge density appearing to be most important (Table 2). When habitat amount was low (6\% coverage), predicted quoll occupancy was 94 times higher at landscapes with the minimum edge density $(0.02 \mathrm{~km} / \mathrm{ha})$ when compared to sites with the maximum edge density $(0.19 \mathrm{~km} / \mathrm{ha})$. By contrast, when habitat amount was high ( $37 \%$ coverage), predicted quoll occupancy was only 7.5 times higher at landscapes with the minimum edge density when compared to sites with maximum edge density (Fig. 2).
Abundance

In the dry season, the best $\mathrm{N}$-mixture model included habitat amount and edge as additive terms, as well as topographical ruggedness (Table S4). Edge density and topographical ruggedness were both important predictors (Table 2). Predicted quoll abundance was 24 when edge density was set to the minimum, and zero when edge density was set to the maximum. Quoll abundance increased from one individual when topographical ruggedness was set to the minimum (0.32) to 20 when topographical ruggedness was set to the maximum (2.04) (Fig. 3). In the wet season, the best model was similar to the best dry season model, with the addition of total rainfall in previous wet season. Edge density, topographical ruggedness, and total rainfall in previous wet season were all strongly influential predictors of abundance. Predicted abundance was six times higher at landscapes that received the maximum amount of previous wet season rainfall (400 mm) (6 individuals CI 3-14) when compared to landscapes that received the minimum amount of previous wet season rainfall $(160 \mathrm{~mm})(0$ individuals $\mathrm{CI}$ 0-2) (Fig. 4). Average predicted landscape abundance was eight individuals $(\min =0, \max =71)$ in the dry
Table 2 Summary tables from occupancy and $\mathrm{N}$-mixture models, used to test northern quoll (Dasyurus hallucatus) responses to naturally fragmented landscapes in the Pilbara bioregion, Western Australia

Strongly influential results (95\% confidence intervals do not overlap zero) are indicated in bold

\begin{tabular}{|c|c|c|c|c|c|}
\hline & Variable & Estimate & SE & Lower CI & Upper CI \\
\hline & Occupancy & & & & \\
\hline \multirow[t]{5}{*}{ Dry season } & Intercept & 9.76 & 4.68 & -9.08 & 9.28 \\
\hline & Habitat amount & -1.49 & 0.49 & -0.98 & 0.95 \\
\hline & Edge density & -6.24 & 2.00 & -3.98 & 3.86 \\
\hline & Proportion recently burnt & -5.61 & 1.21 & -2.42 & 2.31 \\
\hline & Topographical ruggedness & 13.13 & 3.55 & -6.83 & 7.09 \\
\hline \multirow[t]{5}{*}{ Wet season } & Intercept & -6.72 & 0.88 & -8.45 & -5.00 \\
\hline & Habitat amount & 1.89 & 1.05 & -0.16 & 3.94 \\
\hline & Edge density & -2.24 & 1.01 & -4.21 & -0.27 \\
\hline & $\begin{array}{l}\text { Habitat amount*Edge } \\
\text { density }\end{array}$ & 1.53 & 0.78 & 0.01 & 3.06 \\
\hline & $N$-mixture model & & & & \\
\hline \multirow[t]{4}{*}{ Dry season } & Intercept & -5.13 & 0.33 & -5.78 & -4.47 \\
\hline & Habitat amount & -0.16 & 0.18 & -0.52 & 0.19 \\
\hline & Edge density & -1.68 & 0.35 & -2.38 & -0.99 \\
\hline & Topographical ruggedness & 0.98 & $\mathbf{0 . 1 0}$ & 0.78 & 1.18 \\
\hline \multirow[t]{5}{*}{ Wet season } & Intercept & -4.62 & 0.43 & -5.46 & -3.78 \\
\hline & Habitat amount & 0.11 & 0.17 & -0.21 & 0.44 \\
\hline & Edge density & -1.81 & 0.34 & -2.48 & -1.14 \\
\hline & Topographical ruggedness & 0.52 & 0.16 & 0.21 & 0.84 \\
\hline & Previous wet season & 0.74 & 0.14 & 0.47 & 1.01 \\
\hline
\end{tabular}


Fig. 2 Predictions from wet season occupancy models showing the relationship between the probability of northern quoll (Dasyurus hallucatus) occupancy and edge density at landscapes with low $(<15 \%)$, medium (15-25\%), and high (>25\%) amounts of rocky habitat in the Pilbara bioregion, Western Australia
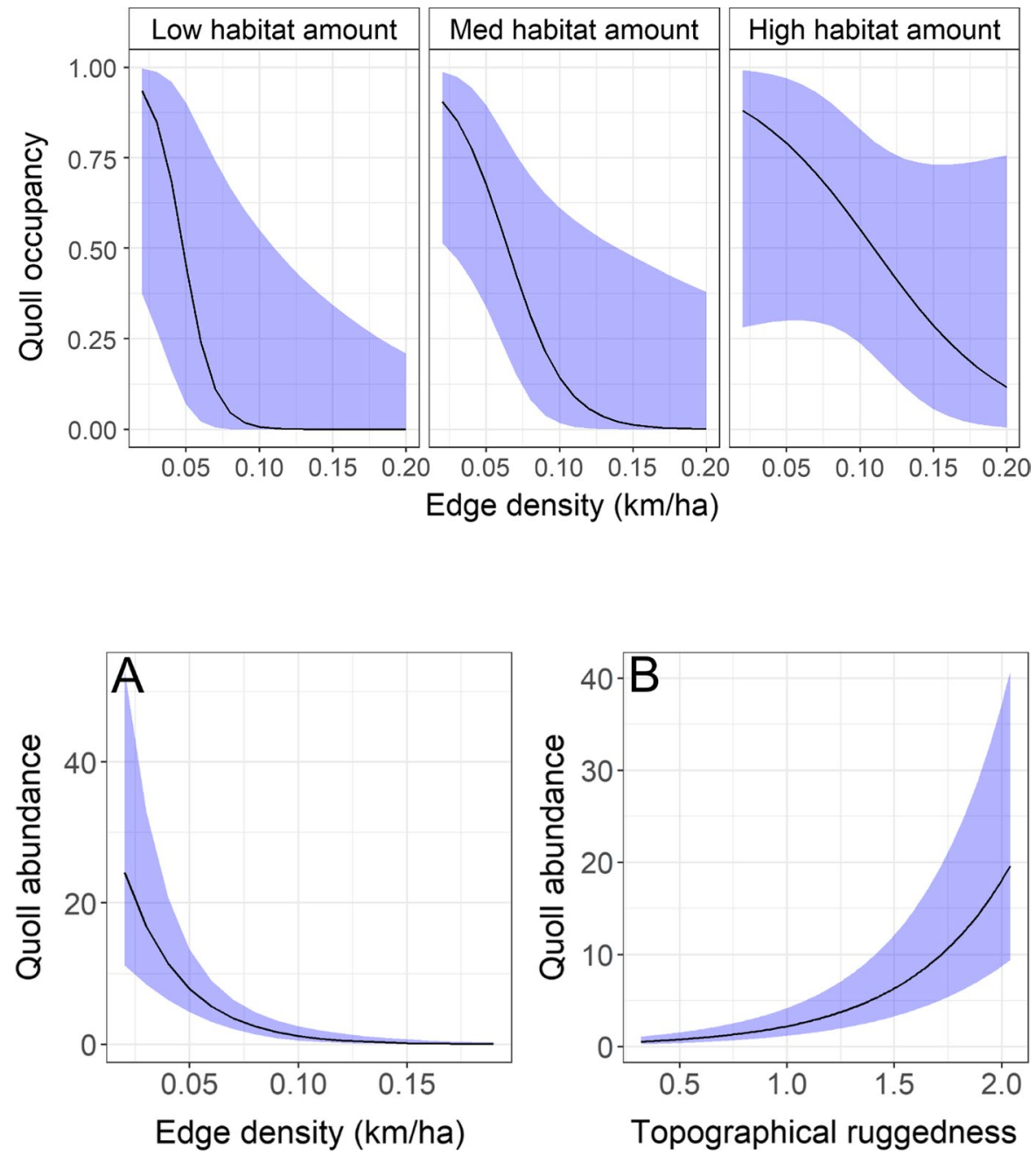

Fig. 3 Predictions from dry season $\mathrm{N}$-mixture models, used to test northern quoll (Dasyurus hallucatus) responses to naturally fragmented landscapes in the Pilbara bioregion, Western Australia. Northern quoll responses to A edge density, and $\mathbf{B}$ topographical ruggedness
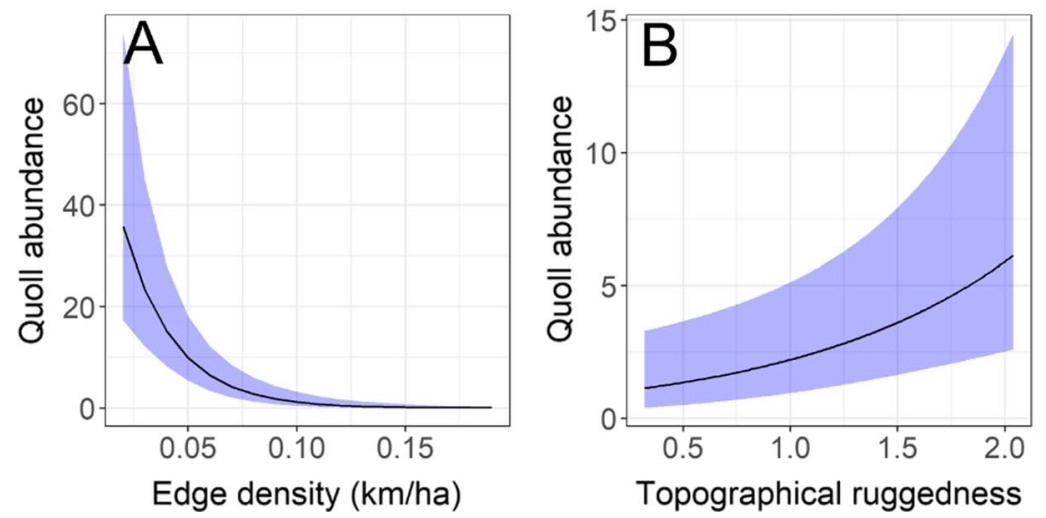

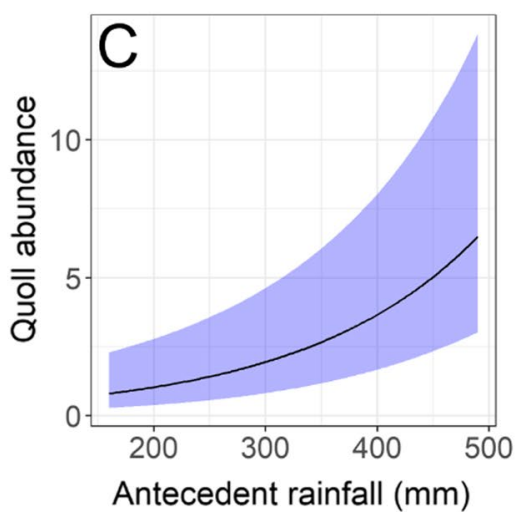

Fig. 4 Predictions from wet season N-mixture models, used to test northern quoll (Dasyurus hallucatus) responses to naturally fragmented landscapes in the Pilbara bioregion, Western
Australia. Northern quoll responses to A edge density, B topographical ruggedness and $\mathbf{C}$ previous wet season rainfall (mm) 
season and 10 individuals $(\min =0, \max =71)$ in the wet season (Table S5).

\section{Discussion}

We examined the influence of habitat amount and configuration on the occupancy and abundance of the globally endangered northern quoll across a naturally fragmented landscape. We found that habitat configuration-represented as the density of 'edge' (between rocky outcrops and spinifex sandplain) within a landscape-was the primary driver of quoll occupancy and abundance. By contrast, habitat amount played a negligible role. Northern quolls showed a strong aversion to landscapes with a greater edge component. Our results contrast with a general view of the primacy of habitat amount for species conservation (Hodgson et al. 2011), and suggest that habitat configuration may be important for other species that inhabit small natural features embedded within a matrix of unsuitable habitat (Andren 1994; Betts et al. 2006; Fahrig 2017).

The habitat fragmentation threshold hypothesis underscores the synergistic roles of patch size and isolation when habitat amount is $<30 \%$ (Andren 1994), a criterion that is often met in naturally fragmented landscapes or those comprised of small natural features (Hunter et al. 2017). Andren (1994) recognised mobile species that utilise multiple patches within a landscape as an example of how configuration impacts can be exacerbated when habitat is sparse. In landscapes where habitat patches are smaller than an animal's home range, the animal must travel among multiple patches in order to acquire sufficient resources-performing landscape supplementation, sensu Dunning et al. (1992). The need to undertake landscape supplementation in fragmented landscapes is heightened for predators, which require large areas of habitat to meet their energetic needs (McNab 1963; Tucker et al. 2014). In the Pilbara, the average female northern quoll home range can exceed 30 hectares (Cowan et al. 2020; Hernandez-Santin et al. 2020), an area far larger than the average patch size in our study area (0.69 ha). However, not all predators are equally sensitive to habitat fragmentation. In human-modified fragmented landscapes, small to medium-sized predators often fare better than top-tier predators (Crooks 2002).
An important aspect of the spatial context of small natural features is connectivity among patches, and there are two major consequences of increased matrix use when connectivity between habitat patches is reduced. First, animals expend more energy travelling between dispersed habitat patches, leaving less energy for reproduction or rearing offspring, and potentially leading to reduced population size. Second, increased time moving within unsuitable habitat between patches can increase perceived and actual predation risk (Johnson et al. 2009). For example, based on giving up density experiments, prey species such as rock hyraxes (Procavia capensis), Franklin's ground squirrel (Poliocitellus franklinii), and Mitchell's hopping mice (Notomys mitchellii) perceive more risk in non-preferred structurally simple habitat when compared to preferred structurally complex habitat, likely because they are more vulnerable to predation in simple habitat (Druce et al. 2006; Duggan et al. 2012; Doherty et al. 2015). This is also likely to be the case for quolls because their primary predator-feral cats-are more common in the spinifex matrix (Hernandez-Santin et al. 2016), as well as being more efficient hunters in simplified environments (McGregor et al. 2015). The combination of increased energy costs and predation risk in fragmented landscapes are also likely to limit the northern quolls' capacity to disperse, which can in turn limit gene flow, and increase the effects of processes such as genetic drift and inbreeding. We suggest further research is required to assess the impact of these factors on northern quoll dispersal given our current lack of understanding and the propensity of northern quolls to occur in naturally fragmented landscapes (Moore et al. 2021a). It is also possible that edges themselves amplify predation risk for quolls, given that elevated rates of predation are common at or near habitat edges (May and Norton 1996; McGregor et al. 2014; Hansen et al. 2019; Hamer et al. 2021).

Fire (proportion of landscape burnt in the last 3 years) did not have a strong effect on quoll occupancy or abundance. One explanation for this is that northern quolls only respond to fire within a period shorter than 3 years, which was not able to be captured in this study. Alternatively, it is possible northern quolls respond to a combination of factors that influence vegetation, such as grazing or predation pressure plus fire, as opposed to fire alone. This explanation is supported by the findings of a previous 
study conducted within the same study area, which found that time since the matrix burnt did not influence patch use by northern quolls (Moore et al. 2021b). However, Moore et al. (2021b) also found that northern quolls use of the matrix increased with increasing spinifex cover, a predictor that could not be included in the current study for logistical reasons. While fire is a major determinant of spinifex cover in Australia (Allan and Southgate 2002; Haslem et al. 2011), vegetation cover within the study area is likely influenced by additional factors, including grazing from introduced herbivores such as cattle (Bos taurus), feral horses (Equus caballus), donkeys (Equus asinus), and camels (Camelus dromedarius)—all of which are common within the study area (McKenzie et al. 2009).

We found topographical ruggedness was an important factor in predicting quoll abundance irrespective of season, supporting previous studies which indicate that areas which are topographically rugged can provide high quality habitat for many of Australia's declining mammal species (Einoder et al. 2018; McDonald et al. 2020; von Takach et al. 2020), including the northern quoll (Braithwaite and Griffiths 1994; Woinarski et al. 2008; Moore et al. 2019). Northern quoll wet season abundance was higher at sites that received higher amounts of rainfall in the previous wet season. This is likely because Pilbara northern quolls align their recruitment period with the peak in annual rainfall (Jan-Mar) (Dunlop per comms) when landscape productivity is at its highest for insects and other prey items (Dunlop et al. 2017) probably to increase recruitment rate (Moro et al. 2019).

\section{Conclusions}

We found that landscape fragmentation is detrimental to quoll occurrence and abundance, likely because quolls are exposed to increased levels of predation in these landscapes. This suggests that further isolation of rocky habitats, through either the construction of mining infrastructure (e.g. roads, rail lines) or other isolating mechanisms will have crucial negative impacts on northern quoll populations. Thus, the spatial configuration of small natural features should be considered as part of impact assessments for organisms that occupy naturally fragmented habitats. Managing the spinifex matrix (i.e. by undertaking managed burns that allow for older spinifex to persist) to increase structural complexity may also benefit quoll populations by reducing the intensity of edge effects as well as predation rates in the matrix. Overall, our findings have important implications for managing organisms that inhabit small natural features as incremental loss of habitat patches will have a disproportionately greater impact than a pure reduction in habitat amount.

Acknowledgements Data collection was assisted by Sian Thorn, Darcy Watchorn, Rainer Chan, Daniel Bohorquez Fandino, Jacob Champney, Hannah Kilian, and the Yandeyarra Indigenous ranger program. Technical support was provided by Neal Birch, Brent Johnson, Hannah Anderson, Russell Palmer, Alicia Whittington, and Jo Williams from the Western Australian Department of Biodiversity, Conservation and Attractions (DBCA), as well as Deb Noy from Charles Sturt University. Equipment and operational costs were provided by DBCA, Roy Hill, and Charles Sturt University. Roy Hill also covered the costs of flights, fuel, and freight.

Author contributions HAM: Conceived and developed ideas, designed and conducted experiments, performed statistical analysis and wrote the manuscript. DRM: Contributed to concept development and manuscript preparation. JAD Conceived and developed ideas, assisted with designing and conducting experiments and contributed to manuscript preparation. LEV: Developed ideas and contributed to manuscript preparation. MAC: Contributed to manuscript preparation. DGN: Conceived and developed ideas, designed experiments, assisted with performing statistical analysis and contributed to manuscript preparation.

Funding Open Access funding enabled and organized by CAUL and its Member Institutions. Equipment and operational costs were provided by DBCA, Roy Hill, and Charles Sturt University. Roy Hill also covered the costs of flights, fuel, and freight.

Data availability All data and code will be available at figshare upon publication.

Code availability All data and code will be available at figshare upon publication.

\section{Declarations}

Conflict of interest No conflicts of interest are declared by the authors.

Ethical approval Charles Sturt University Animal Ethics Committee provided ethics approval (A17031, A18034) for all work involving animals. Regulation 17 Licences to take fauna for scientific purposes (08-002476-1, 08-002475-1) were issued by the Western Australian Department of Biodiversity, Conser- 
vation and Attractions for all research conducted as part of this thesis.

Consent to participate Not applicable.

Consent for publication Not applicable.

Open Access This article is licensed under a Creative Commons Attribution 4.0 International License, which permits use, sharing, adaptation, distribution and reproduction in any medium or format, as long as you give appropriate credit to the original author(s) and the source, provide a link to the Creative Commons licence, and indicate if changes were made. The images or other third party material in this article are included in the article's Creative Commons licence, unless indicated otherwise in a credit line to the material. If material is not included in the article's Creative Commons licence and your intended use is not permitted by statutory regulation or exceeds the permitted use, you will need to obtain permission directly from the copyright holder. To view a copy of this licence, visit http://creativecommons.org/licenses/by/4.0/.

\section{References}

Allan GE, Southgate RI (2002) Fire regimes in spinifex landscapes. In: Flammable Australia: the fire regimes and biodiversity of a continent, vol. 1, pp 145-176

Andren H (1994) Effects of habitat fragmentation on birds and mammals in landscapes with different proportions of suitable habitat: a review. Oikos 71:355-366

Andrén H, Angelstam P, Lindström E, Widen P (1985) Differences in predation pressure in relation to habitat fragmentation: an experiment. Oikos 45:273-277

Bayly I (2011) Australia's granite wonderlands. Bas Publishing, Seaford

Begg RJ (1981) The small mammals of Little Nourlangie Rock, NT III. Ecology of Dasyurus hallucatus, the northern quoll (Marsupialia: Dasyuridae). Wildl Res 8:73-85

Bender DJ, Fahrig L (2005) Matrix structure obscures the relationship between interpatch movement and patch size and isolation. Ecology 86:1023-1033

Bennett AF, Radford JQ, Haslem A (2006) Properties of land mosaics: implications for nature conservation in agricultural environments. Biol Conserv 133:250-264

Betts MG, Forbes GJ, Diamond AW, Taylor PD (2006) Independent effects of fragmentation on forest songbirds: an organism-based approach. Ecol Appl 16:1076-1089

Bleich V, Wehausen J, Holl S (1990) Desert-dwelling mountain sheep: conservation implications of a naturally fragmented distribution. Conserv Biol 4:383-390

BOM (2020) Bureau of Meteorology. https://www.google. $\mathrm{com} / \mathrm{search}$ ?q=BUREAU+OF+METEOROLOGY\&rlz= 1C1CHBF_en-GBAU843AU843\&oq=BUREAU+OF+ METEOROLOGY\&aqs=chrome..69i57j69i59j69i60j69 i61.583j0j4\&sourceid=chrome $\&$ ie $=$ UTF- 8

Braithwaite RW, Griffiths AD (1994) Demographic variation and range contraction in the Northern Quoll,
Dasyurus hallucatus (Marsupialia: Dasyuridae). Wildl Res 21:203-217

Cheptou P-O, Hargreaves AL, Bonte D, Jacquemyn H (2017) Adaptation to fragmentation: evolutionary dynamics driven by human influences. Philos Trans R Soc B 372:20160037

Cowan M, Moro D, Anderson H, Angus J, Garretson S, Morris K (2020) Aerial baiting for feral cats is unlikely to affect survivorship of northern quolls in the Pilbara region of Western Australia. Wildl Res 47:589-598

Cramer VA, Dunlop J, Davis R, Ellis R, Barnett B, Cook A, Morris K, van Leeuwen S (2016) Research priorities for the northern quoll (Dasyurus hallucatus) in the Pilbara region of Western Australia. Aust Mammal 38:135-148

Cremona T, Crowther M, Webb JK (2017) High mortality and small population size prevent population recovery of a reintroduced mesopredator. Anim Conserv 20:555-563

Crooks KR (2002) Relative sensitivities of mammalian carnivores to habitat fragmentation. Conserv Biol 16:488-502

Diete RL, Meek PD, Dixon KM, Dickman CR, Leung LK-P (2016) Best bait for your buck: bait preference for camera trapping north Australian mammals. Aust J Zool 63:376-382

Doherty T, Davis RA, van Etten E (2015) A game of catand-mouse: microhabitat influences rodent foraging in recently burnt but not long unburnt shrublands. J Mammal 96:324-331

Driscoll DA (2005) Is the matrix a sea? Habitat specificity in a naturally fragmented landscape. Ecol Entomol 30:8-16

Druce DJ, Brown JS, Castley JG, Kerley GI, Kotler BP, Slotow R, Knight MH (2006) Scale-dependent foraging costs: habitat use by rock hyraxes (Procavia capensis) determined using giving-up densities. Oikos 115:513-525

Duggan JM, Heske EJ, Schooley RL (2012) Gap-crossing decisions by adult Franklin's ground squirrels in agricultural landscapes. J Mammal 93:1231-1239

Dunlop JA, Rayner K, Doherty TS (2017) Dietary flexibility in small carnivores: a case study on the endangered northern quoll, Dasyurus hallucatus. J Mammal 98:858-866

Dunning JB, Danielson BJ, Pulliam HR (1992) Ecological processes that affect populations in complex landscapes. Oikos 65:169-175

Einoder LD, Southwell DM, Lahoz-Monfort JJ, Gillespie GR, Fisher A, Wintle BA (2018) Occupancy and detectability modelling of vertebrates in northern Australia using multiple sampling methods. PLoS ONE 13:e0203304

Ewers RM, Didham RK (2006) Confounding factors in the detection of species responses to habitat fragmentation. Biol Rev 81:117-142

Fahrig L (1998) When does fragmentation of breeding habitat affect population survival? Ecol Model 105:273-292

Fahrig L (2003) Effects of habitat fragmentation on biodiversity. Annu Rev Ecol Evol Syst 34:487-515

Fahrig L (2017) Ecological responses to habitat fragmentation per se. Annu Rev Ecol Evol Syst 48:1-23

Fiske I, Chandler R (2011) Unmarked: an R package for fitting hierarchical models of wildlife occurrence and abundance. J Stat Softw 43:1-23

Fitzsimons JA, Michael DR (2017) Rocky outcrops: a hard road in the conservation of critical habitats. Biol Conserv 211:36-44 
Geoscience Australia (2008) GEODATA 9 second DEM and D8: digital elevation model version 3 and flow direction grid 2008

Griffiths AD, Brook BW (2015) Fire impacts recruitment more than survival of small-mammals in a tropical savanna. Ecosphere 6:1-22

Haddad NM, Brudvig LA, Clobert J, Davies KF, Gonzalez A, Holt RD, Lovejoy TE, Sexton JO, Austin MP, Collins CD (2015) Habitat fragmentation and its lasting impact on Earth's ecosystems. Sci Adv 1:e1500052

Hamer RP, Gardiner RZ, Proft KM, Johnson CN, Jones ME (2021) A triple threat: high population density, high foraging intensity and flexible habitat preferences explain high impact of feral cats on prey. Proc Royal Soc B 288:20201194

Hansen NA, Sato CF, Michael DR, Lindenmayer DB, Driscoll DA (2019) Predation risk for reptiles is highest at remnant edges in agricultural landscapes. J Appl Ecol 56:31-43

Haslem A, Kelly LT, Nimmo DG, Watson SJ, Kenny SA, Taylor RS, Avitabile SC, Callister KE, Spence-Bailey LM, Clarke MF (2011) Habitat or fuel? Implications of long-term, post-fire dynamics for the development of key resources for fauna and fire. J Appl Ecol 48:247-256

Haynes K, Cronin J (2006) Interpatch movement and edge effects: the role of behavioral responses to the landscape matrix. Oikos 113:43-54

Hernandez-Santin L, Goldizen AW, Fisher DO (2016) Introduced predators and habitat structure influence range contraction of an endangered native predator, the northern quoll. Biol Conserv 203:160-167

Hernandez-Santin L, Henderson M, Molloy SW, Dunlop JA, Davis RA (2020) Spatial ecology of an endangered carnivore, the Pilbara northern quoll. Aust Mammal 43:235-242

Hill BM, Ward SJ (2010) National recovery plan for the northern quoll Dasyurus hallucatus. Department of Natural Resources, Environment, The Arts and Sport, Darwin.

Hill J, Thomas C, Lewis O (1999) Flight morphology in fragmented populations of a rare British butterfly, Hesperia comma. Biol Conserv 87:277-283

Hodgson JA, Moilanen A, Wintle BA, Thomas CD (2011) Habitat area, quality and connectivity: striking the balance for efficient conservation. J Appl Ecol 48:148-152

Hohnen R, Ashby J, Tuft K, McGregor H (2013) Individual identification of northern quolls (Dasyurus hallucatus) using remote cameras. Aust Mammal 35:131-135

Hunter ML, Acuña V, Bauer DM, Bell KP, Calhoun AJ, FelipeLucia MR, Fitzsimons JA, González E, Kinnison M, Lindenmayer D (2017) Conserving small natural features with large ecological roles: a synthetic overview. Biol Conserv 211:88-95

Johnson CA, Fryxell JM, Thompson ID, Baker JA (2009) Mortality risk increases with natal dispersal distance in American martens. Proc R Soc B 276:3361-3367

Kupfer JA (2012) Landscape ecology and biogeography: rethinking landscape metrics in a post-FRAGSTATS landscape. Prog Phys Geogr 36:400-420

Kupfer JA, Malanson GP, Franklin SB (2006) Not seeing the ocean for the islands: the mediating influence of matrixbased processes on forest fragmentation effects. Glob Ecol Biogeogr 15:8-20
Laurance WF, Yensen E (1991) Predicting the impacts of edge effects in fragmented habitats. Biol Conserv 55:77-92

MacKenzie DI, Nichols JD (2004) Occupancy as a surrogate for abundance estimation. Anim Biodivers Conserv 27:461-467

May SA, Norton T (1996) Influence of fragmentation and disturbance on the potential impact of feral predators on native fauna in Australian forest ecosystems. Wildl Res 23:387-400

McDonald PJ, Griffiths AD, Nano CE, Dickman CR, Ward SJ, Luck GW (2015) Landscape-scale factors determine occupancy of the critically endangered central rock-rat in arid Australia: the utility of camera trapping. Biol Conserv 191:93-100

McDonald PJ, Stewart A, Jensen MA, McGregor HW (2020) Topographic complexity potentially mediates cat predation risk for a critically endangered rodent. Wildl Res 47:643-648

McGarigal K, McComb WC (1995) Relationships between landscape structure and breeding birds in the Oregon Coast Range. Ecol Monogr 65:235-260

McGregor R, Stokes V, Craig M (2014) Does forest restoration in fragmented landscapes provide habitat for a wide-ranging carnivore? Animal Conserv 17:467-475

McGregor H, Legge S, Jones ME, Johnson CN (2015) Feral cats are better killers in open habitats, revealed by animalborne video. PLoS ONE 10:e0133915

McKenzie N, Van Leeuwen S, Pinder A (2009) Introduction to the Pilbara biodiversity survey, 2002-2007. Rec West Aust Mus Suppl 78:3-89

McNab BK (1963) Bioenergetics and the determination of home range size. Am Nat 97:133-140

Melo GL, Sponchiado J, Cáceres NC, Fahrig L (2017) Testing the habitat amount hypothesis for South American small mammals. Biol Conserv 209:304-314

Michael D, Lindenmayer D (2018) Rocky outcrops in Australia: ecology, conservation and management. CSIRO PUBLISHING, Melbourne

Molloy SW, Davis RA, Dunlop JA, van Etten E (2017) Applying surrogate species presences to correct sample bias in species distribution models: a case study using the Pilbara population of the Northern Quoll. Nat Conserv 18:27-46

Moore HA, Dunlop JA, Valentine LE, Woinarski JC, Ritchie EG, Watson DM, Nimmo DG (2019) Topographic ruggedness and rainfall mediate geographic range contraction of a threatened marsupial predator. Divers Distrib 25:1818-1831

Moore H, Champney J, Dunlop J, Valentine L, Nimmo D (2020a) Spot on: using camera traps to individually monitor one of the world's largest lizards. Wildl Res 47:326-337

Moore HA, Valentine LE, Dunlop JA, Nimmo DG (2020b) The effect of camera orientation on the detectability of wildlife: a case study from north-western Australia. Remote Sens Ecol Conserv 6:546-556

Moore HA, Dunlop JA, Jolly CJ, Kelly E, Woinarski JC, Ritchie EG, Burnett S, van Leeuwen S, Valentine LE, Cowan MA (2021a) A brief history of the northern quoll (Dasyurus hallucatus): a systematic review. Aust Mammal. https://doi.org/10.1071/AM21002 
Moore HA, Michael DR, Ritchie EG, Dunlop JA, Valentine LE, Hobbs RJ, Nimmo DG (2021b) A rocky heart in a spinifex sea: occurrence of an endangered marsupial predator is multiscale dependent in naturally fragmented landscapes. Landsc Ecol 36:1359-1376

Moro D, Dunlop J, Williams MR (2019) Northern quoll persistence is most sensitive to survivorship of juveniles. Wildl Res 46:165-175

NAFI (2020) Fire history. Northern Australia and Rangelands Fire Information. https://www.firenorth.org.au/nafi3/.

Nakagawa S, Cuthill IC (2007) Effect size, confidence interval and statistical significance: a practical guide for biologists. Biol Rev Camb Philos Soc 82:591-605

Nimmo D, Kelly L, Spence-Bailey L, Watson S, Taylor R, Clarke M, Bennett A (2013) Fire mosaics and reptile conservation in a fire-prone region. Conserv Biol 27:345-353

Nimmo DG, Avitabile S, Banks SC, Bliege Bird R, Callister K, Clarke MF, Dickman CR, Doherty TS, Driscoll DA, Greenville AC, Haslem A, Kelly LT, Kenny SA, LahozMonfort JJ, Lee C, Leonard S, Moore H, Newsome TM, Parr CL, Ritchie EG, Schneider K, Turner JM, Watson S, Westbrooke M, Wouters M, White M, Bennett AF (2019) Animal movements in fire-prone landscapes. Biol Rev Camb Philos Soc 94:981-998

Oakwood M (1997) The ecology of the northern quoll, Dasyurus hallucatus. Ph.D thesis. Australian National University, Canberra

Oakwood M (2004) The effect of cane toads on a marsupial carnivore, the northern quoll, Dasyurus hallucatus. Unpublished Report to Parks Australia North, Darwin

Öckinger E, Lindborg R, Sjödin NE, Bommarco R (2012) Landscape matrix modifies richness of plants and insects in grassland fragments. Ecography 35:259-267

Pollock A (1999) Notes on status, distribution and diet of northern quoll Dasyurus hallucatus in the Mackay-Bowen area, mideastern Queensland. Aust Zool 31:388-395

Porembski S, Barthlott W (2000) Inselbergs: biotic diversity of isolated rock outcrops in tropical and temperate regions. Springer, New York

Potts JM, Elith J (2006) Comparing species abundance models. Ecol Model 199:153-163

QGIS (2020) QGIS geographic information system. Open Source Geospatial Foundation Project.

R Core Team (2020) R: A language and environment for statistical computing. R Foundation for statistical computing, Vienna

Radford IJ, Dickman CR, Start AN, Palmer C, Carnes K, Everitt C, Fairman R, Graham G, Partridge T, Thomson A (2014) Mammals of Australia's tropical savannas: a conceptual model of assemblage structure and regulatory factors in the Kimberley region. PLoS ONE 9:e92341
Reconyx (2020) Reconyx PC900 Hyperfire Professional Covert Camera. https://traps.com.au/product/reconyx-pc900hyperfire-professional-covert-camera/

Reily SJ, DeGloria SD, Elliot RA (1999) terrain ruggedness index that quantifies topographic heterogeneity. Intermt $\mathbf{J}$ Sci 5:23

Richards SA (2008) Dealing with overdispersed count data in applied ecology. J Appl Ecol 45:218-227

Royle JA (2004) N-mixture models for estimating population size from spatially replicated counts. Biometrics 60:108-115

Thomas CD, Hill JK, Lewis OT (1998) Evolutionary consequences of habitat fragmentation in a localized butterfly. J Anim Ecol 67:485-497

Tucker MA, Ord TJ, Rogers TL (2014) Evolutionary predictors of mammalian home range size: body mass, diet and the environment. Glob Ecol Biogeogr 23:1105-1114

Villard MA, Metzger JP (2014) Beyond the fragmentation debate: a conceptual model to predict when habitat configuration really matters. J Appl Ecol 51:309-318

von Takach B, Scheele BC, Moore H, Murphy BP, Banks SC (2020) Patterns of niche contraction identify vital refuge areas for declining mammals. Divers Distrib 26:1467-1482

Watson DM, Peterson AT (1999) Determinants of diversity in a naturally fragmented landscape: humid montane forest avifaunas of Mesoamerica. Ecography 22:582-589

Withers P (2000) Overview of granite outcrops in Western Australia. J R Soc West Aust 83:103

Woinarski J, Oakwood M, Winter J, Burnett S, Milne D, Foster P, Myles H, Holmes B (2008) Surviving the toads: patterns of persistence of the northern quoll Dasyurus hallucatus in Queensland. Report to The Australian Government's Natural Heritage Trust

Woinarski JC, Legge S, Fitzsimons JA, Traill BJ, Burbidge AA, Fisher A, Firth RS, Gordon IJ, Griffiths AD, Johnson CN (2011) The disappearing mammal fauna of northern Australia: context, cause, and response. Conserv Lett 4:192-201

Woinarski J, Burbidge A, Harrison P (2014) The action plan for Australian mammals 2012. Commonwealth Scientific and Industrial Research Organization Publishing, Melbourne

Publisher's Note Springer Nature remains neutral with regard to jurisdictional claims in published maps and institutional affiliations. 